\title{
Why Conservation?
}

\section{BY RICHARD FITTER}

Many people want to conserve wildlife and the countryside for purely aesthetic and moral reasons, because they look nice and are part of our natural heritage, not because conservation has any intrinsic importance or practical value. But conservation is a strictly scientific concept, meaning the maximisation of the flow of energy through any area, so there are also good scientific and economic reasons for conservation, which Richard Fitter, who is Honorary Secretary of the FPS, discusses here.

CONSERVATION generally, and the preservation of wild life in particular, are still too often thought of as a frill, an amenity that ranks low in any realistic scale of values. In fact conservation is all-important to the future welfare of mankind. On good conservation practices depend our future food supply and the increase or even maintenance of the many raw materials we derive ultimately from the soil.

Conservation, as Fraser Darling has pointed out, is basically the maintenance of the flow of energy. Every animal and plant species converts matter into energy, and passes this on to some other species, either directly or indirectly. The science of ecology studies how this is done, and how all the numerous species, from mosses and earthworms to lions and trees, fit into the infinitely complicated web of nature.

Left to itself, nature proceeds over long periods of years in each type of habitat, to an ecological climax which maximises the flow of energy within that habitat. Such natural climaxes are represented by the East African plains with their rich array of ungulate animals, the coniferous woodlands of the taiga that rings the northern hemisphere, and the salt marshes around the coasts of the British Isles. But over most of the developed parts of the globe the natural climaxes have been broken by man. Even the tropical forests are for the most part semi-natural or secondary development, where natural forces work towards a fresh climax but are usually again interrupted before this is reached. In the cultivated parts of the world, man creates his own wholly artificial or at least semi-natural habitats, and imports fresh energy in the shape of domestic animals and fertilisers. But where natural and semi-natural habitats survive, all the wildlife that inhabits them is part of the complex that must be conserved if the flow of energy is to be directed towards a fresh maximum. Every animal and every plant plays its part, or it would not be there ; and none can be eliminated without impairing the ecological succession. This does not mean that they must never be killed, but that they must never be exterminated. They can be cropped, and thus made available as a natural resource for man's use, provided that the rules of conservation are strictly obeyed.

The basic pattern of animal populations that is emerging after the first 
forty years of research into the subject is one of many young being produced each breeding season but only a few surviving. If this were not so, that is if all the young survived, animals would overrun the earth. But the infinitely slow-moving mechanism of evolution works, in a stable population, through this selection of only a small proportion of each generation to survive and form the breeding stock of the next. Thus each winter innumerable wild animals die, because they have proved to be inefficient in some way or other, usually in finding enough food or evading predators. So the first rule of good conservation is to crop each autumn no more animals than would otherwise die. Only if a population is expanding is it permissible to crop more animals than are needed to replace the older adults who will also die during the winter. If the sportsman and the commercial operator adhere to this basic rule, they are benefactors of mankind ; if they do not, they are robbers.

Conservation is thus about animal populations, not about individual animals, which are the province of animal welfare. Conservation is not strictly concerned with cruelty to wild animals, which does not mean that conservationists can disregard the wounding of the human spirit involved in any cruel practices, but that this is a different subject. Only when populations become very small, as with the Javan rhinoceros, down to forty or so individuals, and the red kite in Wales, down to about eighteen pairs, are conservationists concerned with individuals, for then unless the individuals are preserved, the species or local population will be lost.

These are the economic arguments for conservation. But there are others : scientific, aesthetic, and moral. Every species of animal or plant is the repository of knowledge which may ultimately benefit mankind. To exterminate any species, therefore, or to allow it to become extinct by default, is to deprive mankind of scientific knowledge. Who knows what we might not have learned from a scientific study of the dodo or the great auk ? The aesthetic argument for preserving animals and plants is similar to that for preserving beautiful buildings and pictures. It is not usually considered necessary to make a case against pulling down St. Paul's Cathedral to build a block of offices; no more should one need to argue against the destruction of such outstanding natural features as the sea-bird colonies of the Bass Rock or the Farne Islands, or the unspoiled landscape of the Scottish Highlands or the Swiss National Park.

Finally, the moral argument : how can human dignity be maintained if man can only make his way on this planet by dint of destroying the other creatures which inhabit it with him. Man does not live by bread alone, and animals and plants and landscape are not the least important of the words that proceed out of the mouth of God.

\section{Exhibition Emphasises Conservation}

A Wild Life Exhibition with the theme " Living with Nature " will be held at the Alexandra Palace, in London, in April, 1966, organised by the Council for Nature and sponsored by the Observer. The emphasis will be on man's influence on wildlife and the implications for conservation. It is hoped to have outdoor exhibits, including live ones. 